\title{
ARCHIVES
of
}

\section{Comparison of Dental Prostheses Cast and Sintered by SLM from Co-Cr-Mo-W Alloy}

\author{
D. Myszka ${ }^{\text {a, *, M. Skrodzki }}{ }^{\text {b }}$ \\ ${ }^{a}$ Warsaw University of Technology, Faculty of Production Engineering \\ ul. Narbutta 85, 02-524 Warsaw, Poland \\ ${ }^{\mathrm{b}}$ EMES Dental Technique Laboratory, \\ ul. ks. I. Skorupki 5, Ząbki, Poland \\ * Corresponding author. E-mail address: myszkadawid@wp.pl
}

Received 05.04.2016; accepted in revised form 02.09.2016

\begin{abstract}
The article presents the results of a comparative analysis of the metal substructure for dental prosthesis made from a Co-Cr-Mo-W alloy by two techniques, i.e. precision investment casting and selective laser melting (SLM). It was found that the roughness of the raw surface of the SLM sinter is higher than the roughness of the cast surface, which is compensated by the process of blast cleaning during metal preparation for the application of a layer of porcelain. Castings have a dendritic structure, while SLM sinters are characterized by a compact, fine-grain microstructure of the hardness higher by about $100 \mathrm{HV}$ units. High performance and high costs of implementation the SLM technology are the cause to use it for the purpose of many dental manufacturers under outsourcing rules. The result is a reduction in manufacturing costs of the product associated with dental work time necessary to scan, designing and treatment of sinter compared with the time needed to develop a substructure in wax, absorption in the refractory mass, casting, sand blasting and finishing. As a result of market competition and low cost of materials, sinter costs decrease which brings the total costs related to the construction unit making using the traditional method of casting, at far less commitment of time and greater predictability and consistent sinter quality.
\end{abstract}

Keywords: Microstructure, Dental prosthesis, Precision investment casting, Selective laser melting SLM, Dimensional accuracy

\section{Introduction}

Fixed metal-ceramic dental restorations, crowns and bridges are composed of porcelain fused on the surface of metal element, i.e. on a metal cap strictly adhering to the specially prepared walls of the tooth. In some cases, caps resemble a metal thimble or a thin-wall stem, while in other cases they resemble a crown with partly ground surfaces which will be covered with porcelain masking the metal element and reconstructing the full contour of the tooth, thus creating a restoration with satisfactory aesthetic effect (Fig. 1). Metal caps, usually cast, are covered with three layers of porcelain: metal coating porcelain; dentinal porcelain determining the colour or tint of the prosthetic restoration, and enamel porcelain, used to rebuild the incisal edge and the surrounding area.

Metal alloys are the primary material used for dental restorations and prostheses, both fixed and removable. They have been used in dentistry continuously since 1907 [1], when the technique of lost wax (investment) casting was developed. This technique of making castings consists in shaping a model of the future prosthesis in wax material, embedding this model in a refractory coating material, melting out the wax and replacing it with metal introduced by the applied centrifugal force or pressure [2]. In prosthetics it is important to cast a very accurate replica of the wax model, both in terms of the overall dimensions and surface details. 
a)

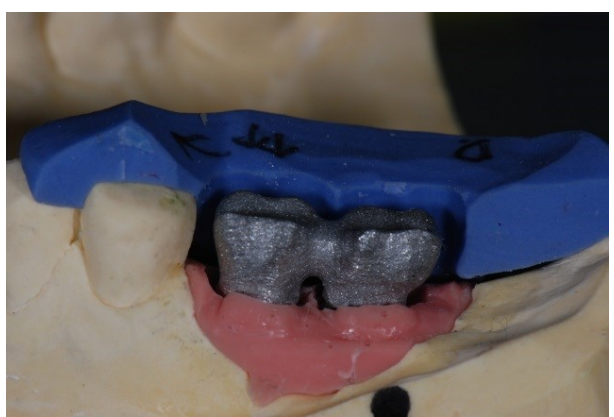

b)

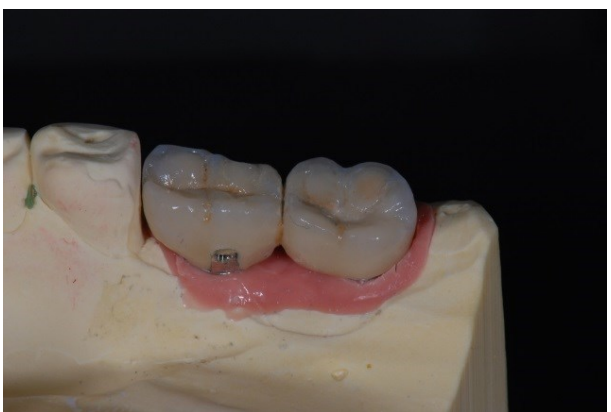

Fig. 1. Fixed metal prosthesis with the layered porcelain coating; a) metal cap, b) metal cap covered with porcelain

The quality of end product (the dental restoration) is largely affected by the manufacturing technique, which means the compliance with relevant conditions at each stage of the casting process, and proper treatment of materials used in this process [3]. It is essential to remember that each modification to the manufacturing technique has a significant impact on the casting quality in terms of its mechanical, physical and chemical properties. The investment casting with a smooth surface and compact internal structure is less susceptible to the effect of the oral cavity environment [2]. The quality of casting made by the lost-wax process depends on factors such as the shrinkage of modelling wax, the expansion of refractory material, the temperature of mould preheating, the thickness and the length of the casting pin, the technique of casting, the shrinkage of the alloy, and the technique by which the finished casting is processed [2]. Despite the complexity of the casting process and subsequent machining of castings, it appears that metal alloys offering high mechanical strength, good machinability and attractive price will hold for a long time the leading position as a base material for prosthetic reconstructions [1]. They can be used to rebuild the lack of a single tooth and also to reconstruct more extensive loss of many teeth. In spite of this, in some aspects of prosthetic reconstruction, modern technologies like 3D printing in metal are also trying to find their way into the range of standard applications. One example technology used in the studies is selective laser melting SLM known since 1995. International standards SLM technology include to the category of laser sintering, although this is confusing because the process completely melts the metal in the entire volume. In contrast, the selective laser sintering (SLS) or direct metal laser sintering (DMLS), which are the real sintering processes. The SLM process uses a standard .stl files, based on which the layered blocks is produced by $3 \mathrm{D}$ printing. The thin metal layer having a thickness of $20 \mu \mathrm{m}$ to $100 \mu \mathrm{m}$ are made of melted powder with a laser beam of high power. The powder is uniformly distributed on the base, which moves in a vertical direction (Z-axis). This process is carried out in a chamber filled with protective gas, eg. nitrogen or argon. The laser beam is directed in the $\mathrm{X}$ and $\mathrm{Y}$ scanning mirrors with high frequency. The laser energy is sufficiently intense to allow full melting of the powder particles. As in other cases, 3D printing in metals such as SLM are dedicated to complex geometries and wall constructions, cavities, complex internal channels in individually made components. Dental restoration are one example of this technology in the industry. It replaces the traditional methods of producing, eg. investment casting. A key role in the replacement of foundry technology plays the type of material and its properties.

\section{Co-Cr-Mo alloys}

The dental prosthetics uses precious metals, common metals and alloys thereof. Precious metals such as gold and platinum were in use for many years, but due to the high price, their use has been gradually reduced. Instead, a stable position in the dental practice have gained the alloys based on cobalt, nickel and titanium. The alloys used most frequently are included in a CoCr-Mo group with carbon content of up to $0.35 \%$. The content of chromium and molybdenum in these alloys is chosen in such a way as to obtain the alloy matrix in the form of $\beta$-Co solution with the A1 structure [8]. Chromium mainly improves the corrosion resistance of alloys. Molybdenum affects the grain refinement and strengthening of the matrix. The addition of carbide-forming alloying elements in the presence of high carbon content causes in these alloys during heat treatment the formation of a structure composed of carbides of the $\mathrm{M}_{7} \mathrm{C}_{3}$ and $\mathrm{M}_{23} \mathrm{C}_{6}$ type $[9,10,11]$. Some physical and mechanical parameters obtained in metal alloys after the casting process differ from the values given by the alloy manufacturer. This reflects the impact of the casting process on alloy properties, in most cases neglected by the manufacturers of such materials in their testing procedure [4]. The dendritic structure is formed as a result of the non-uniform heat dissipation during solidification, due to which the nuclei of crystallization are growing unevenly, and the rate of growth is higher in one direction and lower in another (Fig. 2). In the crystallites there are microsegregations of dendritic cells, while in the interdendritic spaces and along the borders of the crystallites, the primary precipitates of a continuous nature are distributed. The control of mould temperature in the range of $800 \div 1000^{\circ} \mathrm{C}$ affects the grain size in the casting shaped from the molten melt at $1350 \div 1400^{\circ} \mathrm{C}$. At higher temperatures, the coarser structure is formed, which reduces the casting strength. On the other hand, high temperature of the process may result in the formation of large carbides distant from each other, which will produce the material characterized by lower brittleness. Additionally, a good correlation between the strength and ductility is obtained $[4,5]$. 


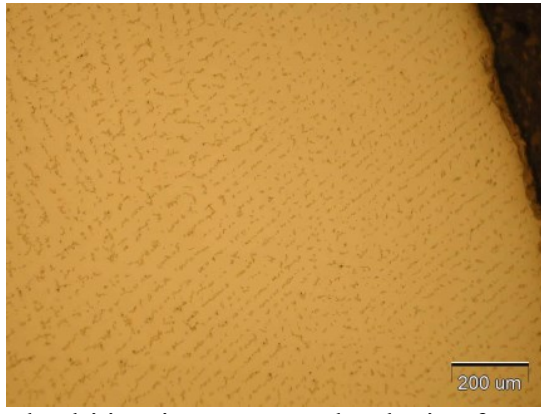

Fig. 2. The dendritic microstructure developing from the casting surface in Co-Cr-Mo-W alloy

The family of cobalt materials widely used in dental applications is represented by Co-Cr-W-Mo alloys. In contrast to the alloys used in orthopaedics, cobalt-based dental alloys are free from the addition of nickel. Tungsten does not affect the fluidity of Co-CrMo alloys but increases the stacking-fault energy (SFE), thus reducing the density of stacking faults [6,7]. Moreover, compared to the Co-Cr-Mo alloys, alloys containing tungsten are characterized by lower thickness of the oxide layer generated in the manufacturing process, which facilitates the combination with ceramics. Therefore they are used for direct firing of the ceramics on metal surface or for acrylic coating. They mainly serve for the manufacture of frame dentures, crowns and bridges [4].

The main aim of this article is to discuss the possibility of replacing the cast metal substructures of dental prostheses with parts made by the process of selective laser melting (SLM). The

a)

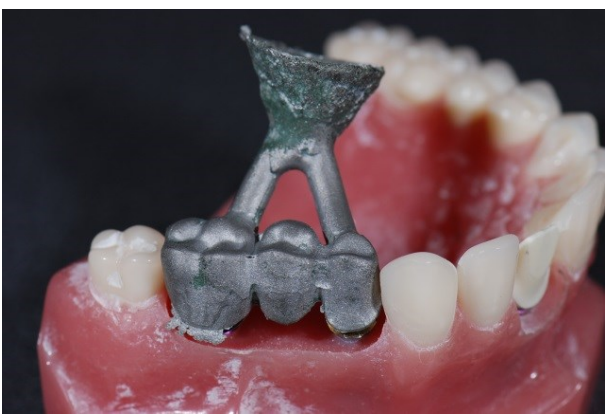

Fig. 3. Substructure reproduced from the designed model; a) investment casting, b) SLM sinter

a)

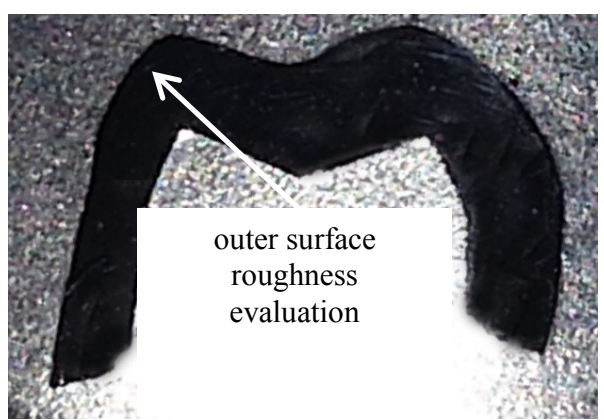

identical substructures made by two different techniques were compared in terms of the structure and properties.

\section{Research methodology}

For tests, the Co-Cr-Mo-W alloys, typically used in prosthetic applications (Table 1), were selected. The substructure was designed virtually after scanning of the model. The next step was making a real substructure by two different methods, i.e. by precision investment casting and by SLM using a $\mathrm{CO}_{2}$ laser (Fig. $3)$. In the preparation of SLM samples a powder with a particle size $\sim 80 \mu \mathrm{m}$ was used, with a density of $8.5 \mathrm{~g} / \mathrm{cm}^{3}$ and a hardness of $420 \mathrm{HV}$ after annealing. Substructure was made on the machine EOSINT M270, where the melting point of the powder was $1410^{\circ} \mathrm{C}$ to $1450^{\circ} \mathrm{C}$. In the method of investment casting the full ceramic molds (based on Bellavest molding mass) were used heated to a temperature of $950^{\circ} \mathrm{C}$ before gravity pouring metal at a temperature of $1460^{\circ} \mathrm{C}$. Each sample were blast cleaned with corundum grit of $250 \mu \mathrm{m}$ granulation in the same manner as the technique used for similar prosthetic frameworks.

Table 1.

Chemical composition of sample substructures prepared for testing [wt \%]

\begin{tabular}{lcccccc}
\hline \multicolumn{1}{c}{ Sample } & Co & Cr & Mo & Si & W & Mn, C \\
\hline SLM sinter & 62 & 28 & 4.2 & 0.5 & 5.2 & $<1 \%$ \\
\hline casting & 62 & 28 & 5.4 & 0.6 & 3.6 & $<1 \%$ \\
\hline
\end{tabular}

b)

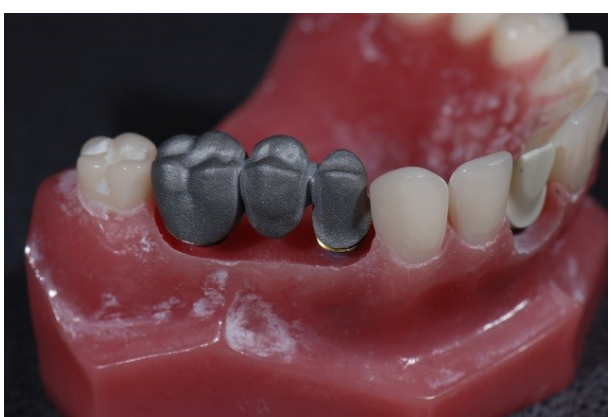

b)

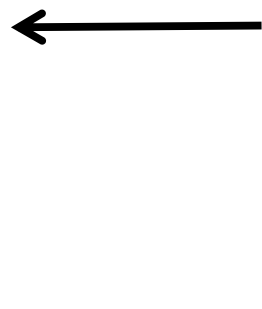

Fig. 4. Characteristic features of the methodology for sample preparation; a) view smuwny une secuon unvugn metal cap, b) view showing the cap surface and the section line 
Surface roughness of the samples was measured with a Nano Focus Surf Explorer confocal microscope. Microstructure was examined on the sample surface and section (Fig. 4) under an Olympus IX70 light microscope and Hitachi 3500N scanning electron microscope.

\section{Results and discussion}

The results of studies indicate that for both parts similar values of the model mapping and surface roughness measurements were obtained (Fig. 5). This is particularly important for the quality of metal-ceramic bond, which is accomplished in the following successive steps of the prosthesis manufacture.

a)

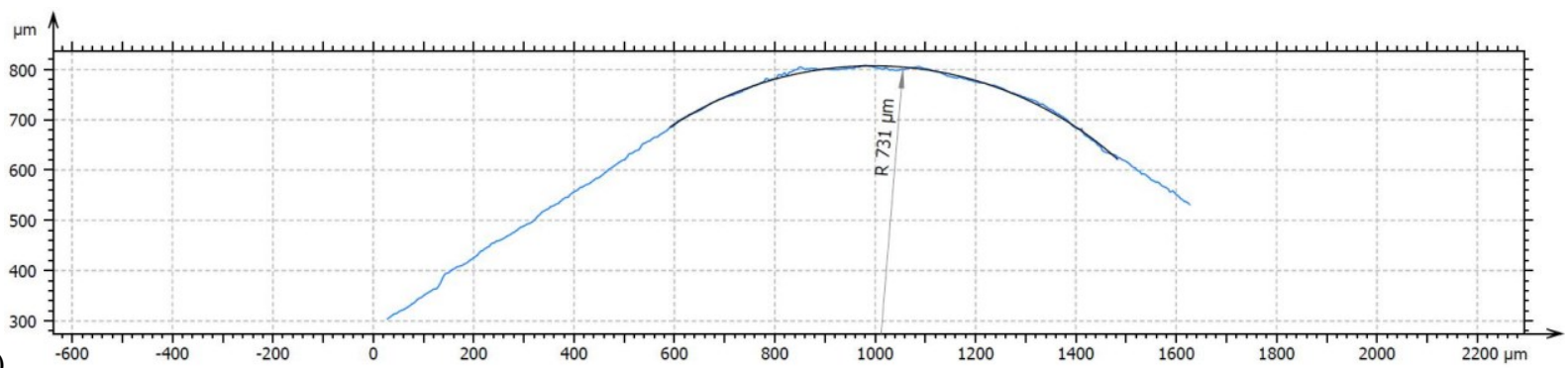

)

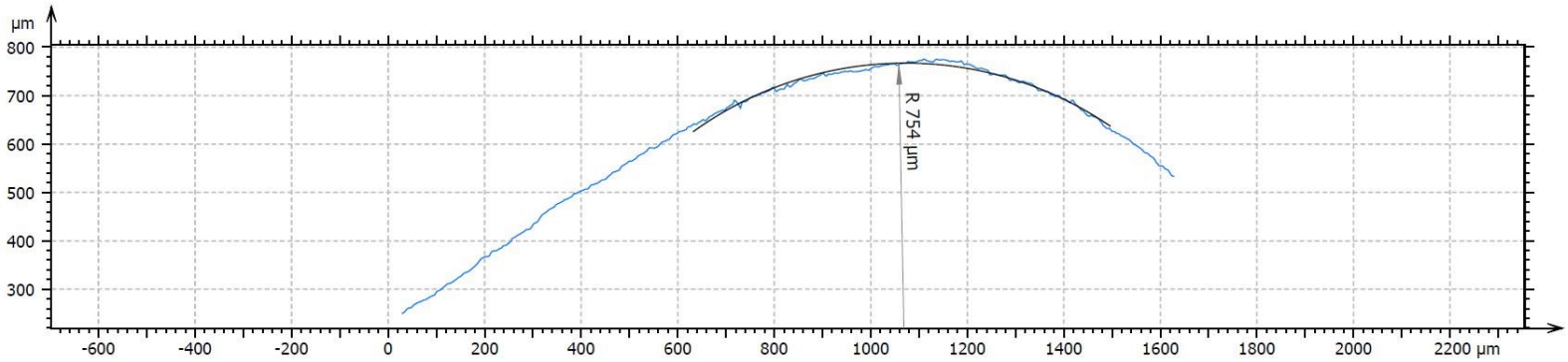

b)

c) Casting $\mathrm{R}_{\mathrm{a}}=7,38 \mu \mathrm{m}$

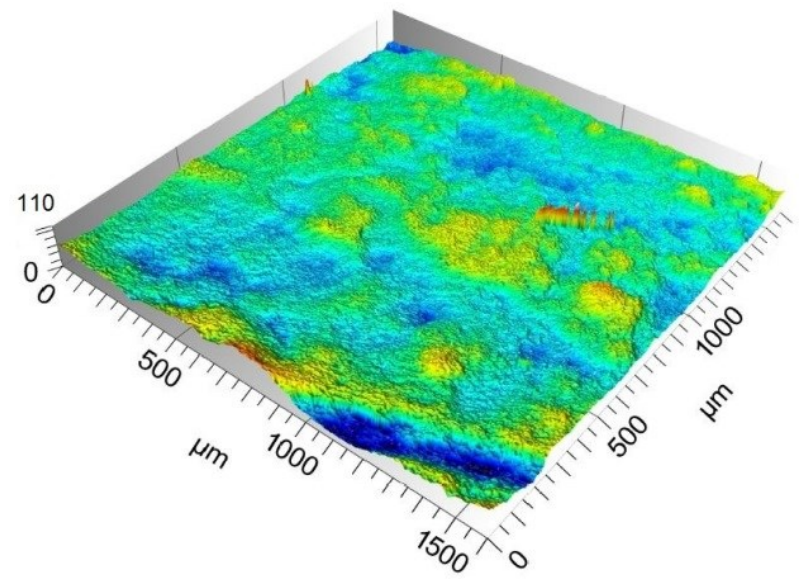

d) Sinter SLM $R_{a}=8,39 \mu \mathrm{m}$

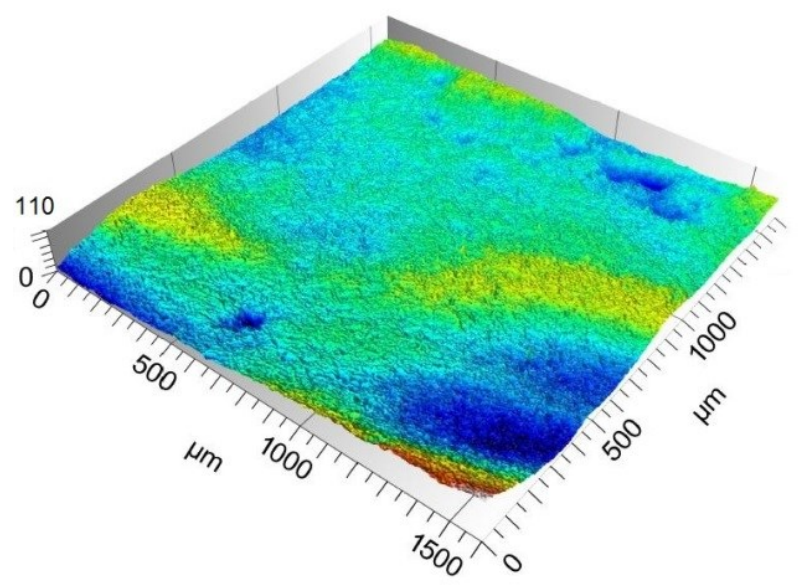

Fig. 5. The results of measurements of the accuracy of mapping and surface roughness; a, c) investment casting, b, d) SLM sinter

The mechanical and chemical treatment of Co-Cr-Mo alloys which are combined with the ceramic material mainly consists in blasting (sandblasting) and etching. For blasting, like in the case of precious metal alloys, corundum sand $\left(\mathrm{Al}_{2} \mathrm{O}_{3}\right)$ is used and the jet of air at a pressure of $0.2 \div 0.3 \mathrm{MPa}$. The size of powder particles affects the resultant surface roughness, and thus also the adhesion of the ceramics fired in the next step of the process $[12,13]$. It has been observed that large grains of the size of $110 \mu \mathrm{m}$ increase the adhesion as compared to the fine grains of 50 $\mu \mathrm{m}$ [14]. The explanation is to be sought in the possible adsorption of very fine particles of aluminium oxide on the surface of alloy. The impurities weakening the metal-ceramic bond were noticed after the blasting process, making additional etching before the application of ceramic layer necessary. This type of surface preparation is sufficient to ensure adequate quality, i.e. the strength and resistance to destruction, of the metal-ceramic bond. Porcelain bonded with metal in the firing process has higher resistance than the porcelain without such substructure. The bond is of an adhesive type, although evidence exists that some sort of reaction also occurs between the porcelain 
and an oxide layer present on the surface of metal. More detailed analysis suggests that stronger porcelain-metal bond can be obtained in an atmosphere saturated with oxygen [15]. Van der Waals forces of attraction are another factor contributing to a strong bond produced between the porcelain and metal. The bond formed between these two materials, mainly of an adhesive nature, is so strong that the destruction or breaking off is to be expected rather in the porcelain and not in the porcelain-metal joint.

A comparison of the surface cast and sintered by SLM demonstrated a better finish of the cast surface, but after sand blasting the surface of the sinter has become more homogeneous (Fig.6.). It seems, however, that this condition may be due to abrasion or deformation and flattening of small bumps in the

a)

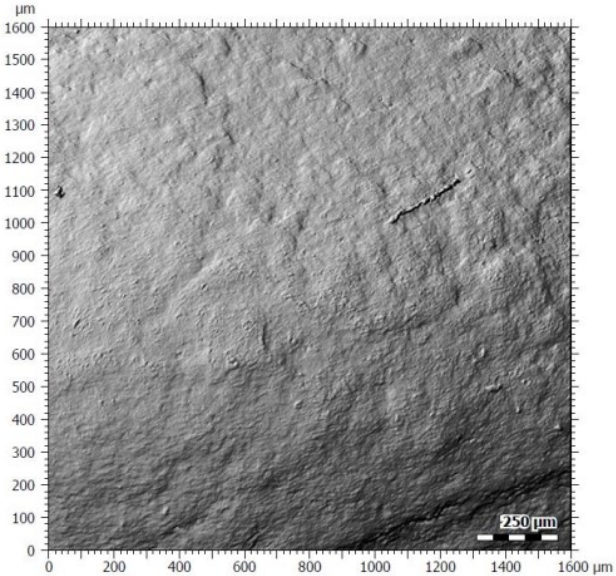

surface of the sintered product (Fig. 7). In microscale, the difference in the quality of both surfaces is clearly visible in the section of casting and sinter (Fig. 8). More detailed examinations also reveal the presence of defects typical of products made by these techniques. Castings are commonly observed to suffer from the microporosity or shrinkage porosity defects appearing in the hot spots. These defects do not occur in the SLM sinters. In sinters, only small isolated pores are observed, which do not deteriorate the quality of the manufactured product, indicating rather a high accuracy of the layer-by-layer fusion of the powdered alloy. This creates a homogeneous structure characterized by very high accuracy and high mechanical strength (Figs.8c and 9).

Fig. 6. View of the metal cap surface in the place of roughness measurement;

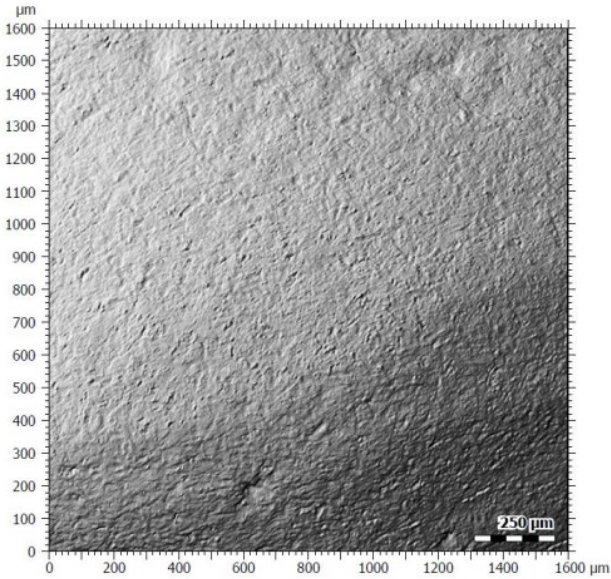

a) investment casting, b) SLM sinter

a)

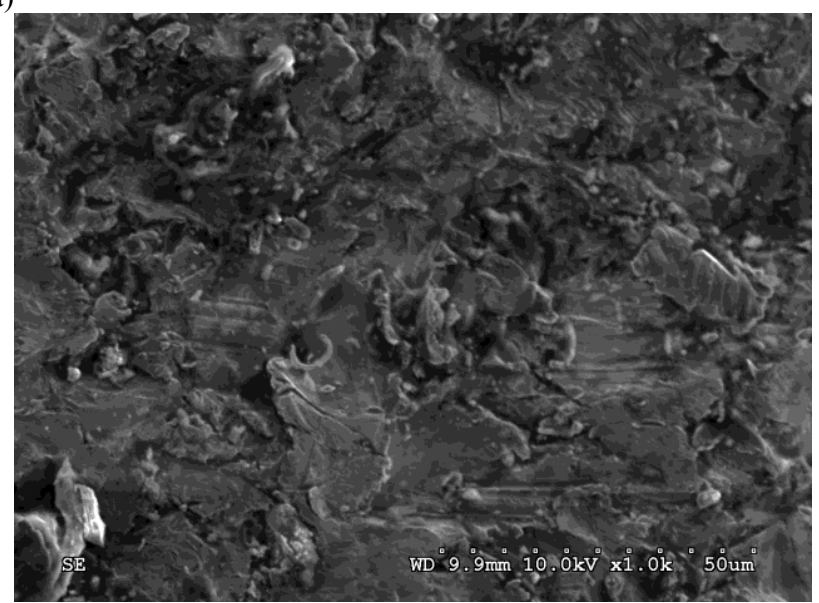

b)

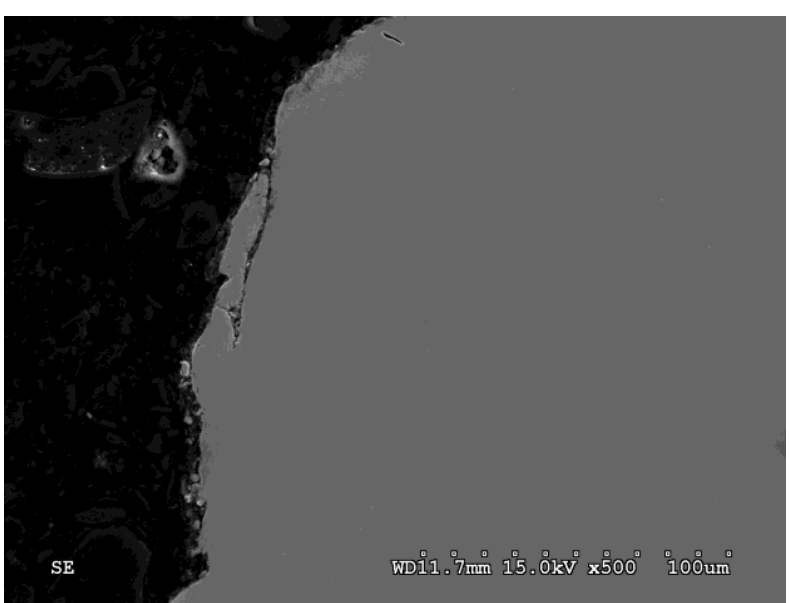

Fig. 7. View of the (a) surface and (b) cross section through the edge of SLM sinter 
a)

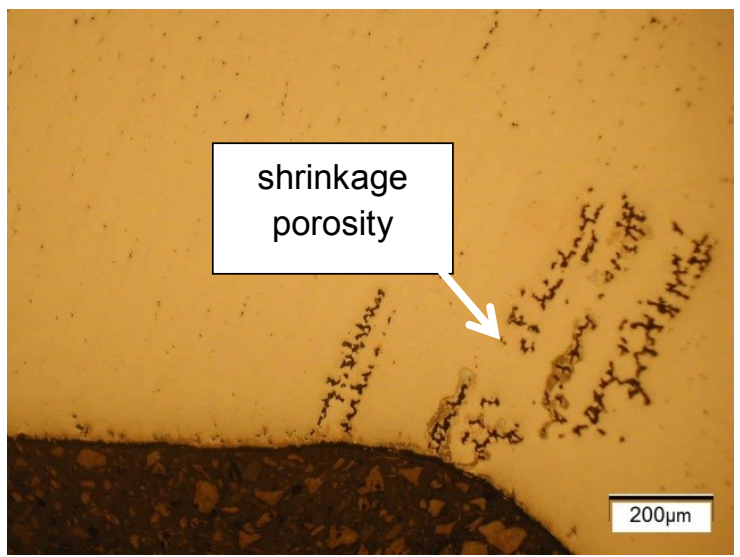

c)

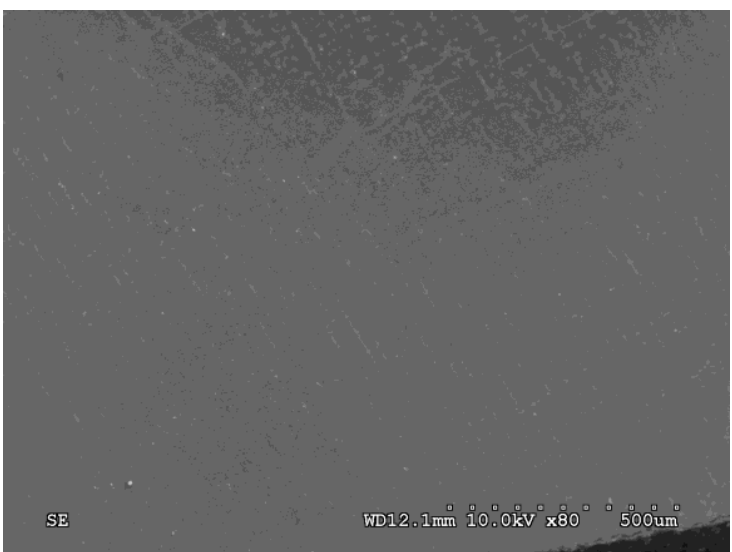

b)

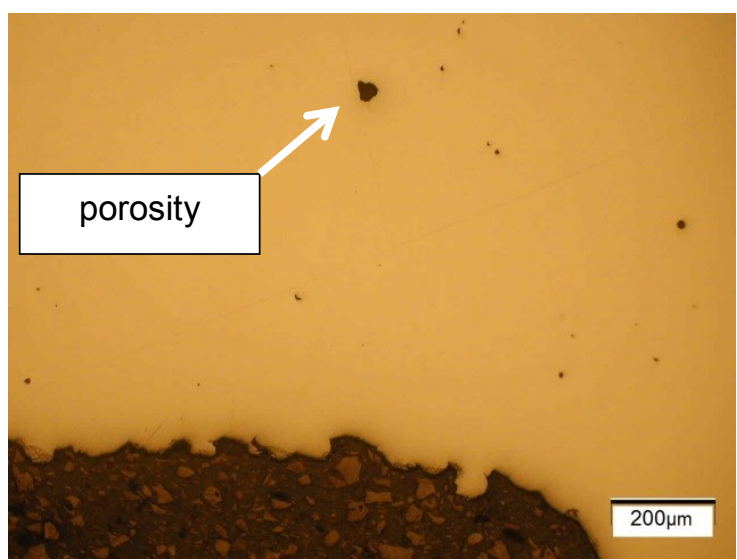

d)

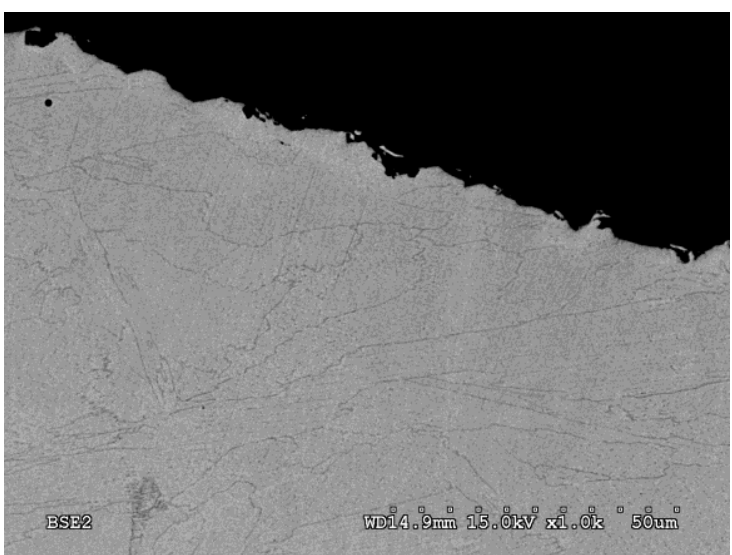

Fig. 8. View of microstructure on the section of sample casting $(a, c)$ and SLM sinter $(b, d)$

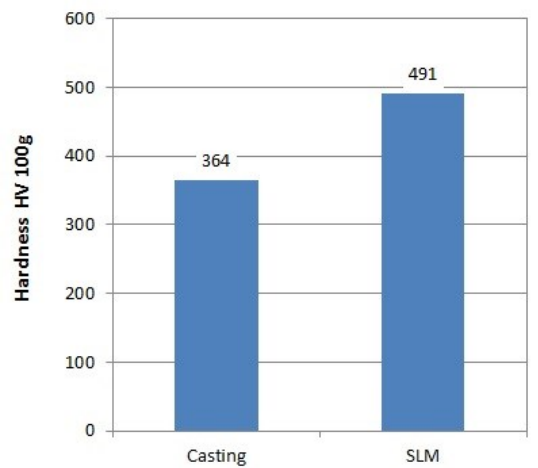

Fig.9. Average hardness of casting and SLM sinter

Fixed dental prostheses with fired layer of porcelain are commonly accepted by the clinical practice mainly due to their high strength and resistance to destruction. Porcelain bonded with metal in the firing process is in fact stronger than the porcelain without such substructure. The bond is of an adhesive nature, and therefore quality of the metal surface is so important. On the other hand, evidence exists to indicate that some sort of bond is also formed between the porcelain and an oxide layer present on the surface of metal. Some observations suggest that stronger porcelain-metal bond can be obtained in an atmosphere saturated with oxygen. Van der Waals forces of attraction are another factor contributing to a strong bond produced between the porcelain and metal. The bond formed between these two materials, mainly of an adhesive nature, is so strong that the destruction or breaking off is to be expected rather in the porcelain and not in the porcelain-metal joint.

It would be a mistake in the discussion of metal restorations coated with fired porcelain to focus attention on the properties of the porcelain only, as some properties of the metal alloy used in the restorations play no less important role. First of all, metal and porcelain should have compatible characteristics in the range of melting temperatures and coefficients of thermal expansion. The coefficient of thermal expansion of the conventional cobalt alloys is relatively high and amounts to $14 \div 15.9 \times 10^{-6} / \mathrm{K}\left(14 \div 14.2 \times 10^{-}\right.$ ${ }^{6} / \mathrm{K}$ for the Co-Cr-Mo-W alloys), while common dental porcelain shows a lower value of $6.7 \div 13.7 \times 10^{-6} / \mathrm{K}$. It has been proved that the permissible difference between these two coefficients should not exceed $0.5 \times 10^{-6} / \mathrm{K}$. Larger differences may induce the formation of shear stress weakening the bond between these two materials. 


\section{Summary}

The article presents the results of a comparative analysis of the metal substructure for dental prosthesis made from a Co-Cr-Mo$\mathrm{W}$ alloy by two techniques, i.e. by precision investment casting and selective laser melting (SLM). It was found that the roughness of the raw surface of the SLM sinter is higher than the roughness of the cast surface, which is compensated by the process of blast cleaning during metal preparation for the application of a layer of porcelain. The microstructure of the two products is also different. The structure of casting is dendritic with numerous carbide precipitates, while the structure of sinter is compact, fairly refined and lacking the orientation typical of the cast structure. In the structure of the sinter, fine and scarce defects of the type of gas porosity were identified, while the predominant type of defects found in the structure of casting was shrinkage porosity present in the hot spots and accompanied by small surface discontinuities. High performance and high costs of implementation the SLM technology are the cause to use it for the purpose of many dental manufacturers under outsourcing rules. The result is a reduction in manufacturing costs of the product associated with dental work time necessary to scan, designing and treatment of sinter compared with the time needed to develop a substructure in wax, absorption in the refractory mass, casting, sand blasting and finishing. As a result of market competition and low cost of materials, sinter costs decrease which brings the total costs related to the construction unit making using the traditional method of casting, at far less commitment of time and greater predictability and consistent sinter quality.

\section{Acknowledgements}

The authors thank Mr Tomasz Borowski, PhD, Eng., for his help in capturing the metallographic images and OPTA-TECH Company for sharing the confocal microscope.

\section{References}

[1] Sosnowska-Tomczyk, E. (2007). Metal alloys used in prosthetics - advantages and disadvantages. Twój Przegląd Stomatologiczny. 5, 30-34. (in Polish).

[2] Spiechowicz, E. (1980). Modern laboratory procedures in dental prosthetics. Warszawa: Państwowy Zakład Wydawnictw Lekarskich. (in Polish).
[3] Rosenstiel, S.F., Land, M.F., Fujimoto, J. (2002). Modern prostheses fixed. Lublin. CZELEJ. (in Polish).

[4] Craig, R.G., Powers, J.M., Wataha, J.C. (2000). Dental materials. Wrocław: Wyd. Medyczne Urban \& Partner. (in Polish).

[5] Bronzino, J.D. (2000). The Biomedical Engineering HandBook, (2 ed.). Boca Raton: CRC Press LLC.

[6] Karaali, A., Mirouh, K., Hamamda, S. \& Guiraldenq, P. (2005). Effect of tungsten $0-8$ wt.\% on the oxidation of $\mathrm{Co}-$ $\mathrm{Cr}$ alloys. Computational Materials Science. 33(1), 37-43. DOI: 10.1016/j.commatsci.2004.12.025.

[7] Carreiro, A. F. (2005). Evaluation of the castability of a CoCr-Mo-W alloy varying the investing technique. Brazilian Dental Journal. 16(1), 50-55. DOI: 10.1590/S010364402005000100009

[8] Clemow, A.J.T., Daniell, B.L., (1979). Solution treatment behavior of Co-Cr-Mo alloy. J. Biomed. Mater. Res. 13(2), 265-279. DOI: $10.1002 / \mathrm{jbm} .820130208$.

[9] Marti, A. (2000). Cobalt-base alloys used in bone surgery. Injury, 31(4), D18-D21. DOI:10.1016/S00201383(00)80018-2.

[10] Bojar, Z. \& Przetakiewicz, W. (1989). Formation of the microstructure of the casting cobalt alloy type Vitalium intended for surgical implants. Mechanik. 9, 419-422. (in Polish).

[11] Bojar, Z. (1992). Analysis of the influence of the structure on the corrosion resistance and fracture mechanism of cobaltbase alloys of type Vitalium. Warszawa: WAT (in Polish).

[12] Gilbert, J.L., Covey, D.A. \& Lautenschlager, E.P. (1994). Bond characteristics of porcelain fused to milled titanium. Dental Materials. 10, 134-140. DOI: 10.1016/01095641(94)90054-X.

[13] Reyes, M.J., Oshida, Y., Andres, C.J., Barco, T., Hovijitra, S. \& Brown, D. (2001). Titanium porcelain system. Part III: effects of surface modification on bond strengths. Biomed. Mater. Eng. 11, 117-136.

[14] Schmage, P., Nergiz, I., Herrmann, W. \& Özcan, M. (2003). Influence of various surface-conditioning methods on the bond strength of metal brackets to ceramic surfaces. American Journal of Orthodontics and Dentofacial Orthopedics. 123(5), 540-546. DOI: 10.1016/S0889. 5406(02)56911-0

[15] Surowska, B. (2009). Biomaterials metal and metal-toceramics in dental applications. Lublin: Wydawnictwo Politechniki Lubelskiej. (in Polish). 